\title{
ANALISIS KOINTEGRASI JUMLAH WISATAWAN, INFLASI, DAN NILAI TUKAR TERHADAP PRODUK DOMESTIK REGIONAL BRUTO (PDRB) POVINSI BALI
}

\author{
Made Aristiawan Jiwa Atmaja ${ }^{\S 1}$, I Putu Eka N. Kencana ${ }^{2}$, G.K. Gandhiadi ${ }^{3}$ \\ ${ }^{1}$ Jurusan Matematika, Fakultas MIPA - Universitas Udayana [Email: aristiawan70@ gmail.com] \\ ${ }^{2}$ Jurusan Matematika, Fakultas MIPA - Universitas Udayana [Email: i.putu.enk@ gmail.com] \\ ${ }^{3}$ Jurusan Matematika, Fakultas MIPA - Universitas Udayana [Email: gandhiadigk@yahoo.com] \\ ${ }^{\S}$ Corresponding Author
}

\begin{abstract}
This paper aimed to determine long-run equilibrium the tourist arrivals, inflation, exchange rate and gross domestic regional product (GDRP) of Bali Province used Johansen's cointegration test. First examined whether each stationary variables using augmented dickey fuller (ADF) test. ADF test showed GDRP of Bali, tourist arrivals, and exchange rate are not stationary, so it is assumed stationary in first lag or I(1). While inflation is stationary in level or I(0). Johansen's cointegration test showed the tourist arrivals, inflation, exchange rate and GDRP of Bali are not cointegrated. Notice that there is no long-run equilibrium, it can not be concluded for structural equation models.
\end{abstract}

Keywords: ADF test, tourist arrivals, exchange rate, inflation, gross domestic regional product, Johansen's cointegration test.

\section{PENDAHULUAN}

Engle dan Granger mendefinisikan konsep kointegrasi sebagai keseimbangan jangka panjang pada variabel runtun waktu (Engle \& Granger [4]). Variabel yang saling terkointegrasi dikatakan dalam kondisi keseimbangan jangka panjang (long-run equilibrium), sedangkan untuk jangka pendek perlu diperhitungkan adanya fluktuasi atau lonjakan variabel jangka pendek. Metode yang diperkenalkan oleh (Engle \& Granger [4]) dapat digunakan untuk mengoreksi ketidakseimbangan (disequilibrium) jangka pendek menuju keseimbangan jangka panjang yang disebut Error Correction Model (ECM).

Jika dilihat berdasarkan jumlah variabel yang terkointegrasi, kointegrasi dibagi menjadi dua, yaitu kointegrasi bivariat dan multivariat. Dalam konsep kointegrasi bivariat, hanya terdapat dua buah variabel yang terkointegrasi, sehingga akan terdapat satu vektor kointegrasi. Konsep kointegrasi multivariat banyak diterapkan pada model ekonomi karena hubungan kointegrasi banyak terjadi pada tiga variabel ekonomi atau lebih. Suatu metode diperkenalkan oleh (Gujarati [5]) untuk menguji kointegrasi multivariat, yaitu uji kointegrasi Johansen. Uji kointegrasi Johansen dapat mendeteksi adanya vektor kointegrasi yang lebih dari satu, sehingga dapat menentukan secara langsung variabel mana saja yang terkointegrasi dan berapa banyak hubungan kointegrasi yang terjadi dari jumlah variabel yang ada.

Pada penelitian ini uji kointegrasi Johansen digunakan untuk melihat keseimbangan jangka panjang pada variabel jumlah kunjungan wisman, inflasi, dan nilai tukar terhadap PDRB Provinsi Bali.

\section{TINJAUAN PUSTAKA}

\subsection{Definisi Runtun Waktu}

Runtun waktu adalah himpunan barisan pengamatan yang terurut dalam waktu, dengan 
jarak interval waktu yang sama (Box \& Jenkins [1]). Barisan pengamatan tersebut dinyatakan dengan $Y_{t_{1}}, Y_{t_{2}}, \ldots, Y_{t_{n}}$. Jadi, $Y_{t_{i}}$ menyatakan pengamatan pada waktu $t_{i}$ dengan $Y$ adalah peubah acak (random variable). Proses stokastik merupakan bagian dari indeks waktu peubah-peubah acak $Y(\omega, t)$, dengan $\omega$ menyatakan ruang sampel dan $t$ menyatakan himpunan indeks waktu.

\subsection{Kestasioneran}

Suatu proses stokastik dikatakan stasioner jika rataan dan variansnya konstan sepanjang waktu, serta nilai kovarians antara dua periode waktu hanya bergantung pada jarak (lag) antara kedua periode waktu itu $\left(Y_{t}, Y_{t+k}\right)$. Variabel runtun waktu dikatakan stasioner jika memenuhi kondisi-kondisi sebagai berikut:

1. Rata-rata $: E\left(Y_{t}\right)=\mu$

2. Varians $: \operatorname{var}\left(Y_{t}\right)=E\left(Y_{t}-\mu\right)^{2}=\sigma^{2}$

3. Kovarians : $\gamma_{k}=E\left[\left(Y_{t}-\mu\right)\left(Y_{t+k}-\mu\right)\right]$

Apabila dilakukan analisis pada data yang tidak stasioner, maka akan memberikan hasil regresi yang palsu atau disebut regresi lancung (spurious regression) (Enders [3]). Regresi lancung adalah situasi dimana hasil regresi menunjukkan koefisien regresi yang signifikan secara statistik dan nilai koefisien determinasi yang tinggi, namun hubungan antara variabel di dalam model tidak saling berhubungan (Enders [3]). Oleh karena itu, langkah pertama yang dilakukan adalah menguji dan membuat data runtun waktu tersebut stasioner.

\subsection{Unit Root Test}

Untuk menguji kestasioneran data, dapat dilakukan dengan beberapa metode pengujian akar unit (unit root test). Pengujian unit root yang dimaksudkan adalah untuk menguji apakah koefisien tertentu dari model autoregressive yang ditaksir memiliki nilai satu atau tidak. Metode pengujian yang digunakan adalah Dickey-Fuller (DF), ataupun Augmented Dickey-Fuller (ADF). Konsep uji DF adalah menguji apakah suatu runtun waktu merupakan proses random walk atau bukan. Random walk merupakan proses stokastik yang tidak stasioner.

Misalkan $Y_{t}$ mengikuti model $\operatorname{AR}(1)$ berikut:

$$
Y_{t}=\mu+\varphi_{1} Y_{t-1}+v_{t}
$$

dengan $\mu$ merupakan parameter $d r i f t, v_{t}$ adalah residual yang bersifat acak atau stokastik dengan rataan nol, varians konstan $v_{t}$ yang bersifat acak dapat dikatakan sebagai white noise. Jika $\varphi_{1}=1$ maka variabel acak $Y_{t}$ mempunyai unit root. Jika data runtun waktu mempunyai unit root maka dikatakan data tersebut bergerak secara acak (random walk) dan data random walk bersifat tidak stasioner. Jika pada persamaan (1) kedua ruas dikurangi dengan $Y_{\mathrm{t}-1}$ maka diperoleh,

$$
\begin{aligned}
Y_{t}-Y_{t-1} & =\mu+\left(\varphi_{1}-1\right) Y_{t-1}+v_{t} \\
\Delta Y_{t} & =\mu+\rho Y_{t-1}+v_{t} .
\end{aligned}
$$

dengan $\rho=(\varphi-1)$ dan $\Delta Y_{t}=Y_{t}-Y_{t-1}$

Teknik pengujian unit root dilakukan dengan membentuk regresi antara $\Delta Y_{t}$ dan $Y_{t-1}$. Dickey dan Fuller menetapkan tiga bentuk model regresi berikut (Gujarati [5]):

$$
\begin{aligned}
& \Delta Y_{t}=\rho Y_{t-1}+v_{t} \\
& \Delta Y_{t}=\mu+\rho y_{t-1}+v_{t} \\
& \Delta Y_{t}=\mu+\beta_{t}+\rho y_{t-1}+v_{t}
\end{aligned}
$$

Model (3) tidak mengandung komponen deterministik, model (4) mengandung konstanta, dan model (5) mengandung konstanta dan tren waktu. Pada semua bentuk model di atas, jika parameter $\rho=0$ maka runtun $Y_{t}$ mengandung unit root. Kekurangan dari Dickey-Fuller Test adalah dengan mengasumsikan bahwa komponen galat $v_{t}$ tidak berkorelasi. Untuk mengantisipasi adanya korelasi tersebut, Dickey \& Fuller [2] mengembangkan pengujian Dickey-Fuller menjadi Augmented Dickey-Fuller (ADF). Model regresi yang akan digunakan untuk melakukan uji ADF, yaitu

$$
\Delta Y_{t}=\mu+\rho Y_{t-1}+\sum_{i=1}^{m} \phi_{i} \Delta Y_{t-i}+v_{t}
$$

dengan $\rho=\sum_{i=1}^{p} \phi_{i}-1$ dan $\phi_{i}=-\sum_{j=i+1}^{m} \varphi_{j}, v_{t}$ adalah variabel gangguan, dan $\mathrm{m}=\mathrm{p}-1$ adalah panjang lag.

Hipotesis yang diuji:

$$
\begin{aligned}
& H_{0}: \rho=0, \\
& H_{1}: \rho<0 .
\end{aligned}
$$


Statistik uji $\tau$ diperoleh dengan

$$
\tau=\frac{\sum_{i=1}^{p} \varphi_{i}-1}{\text { std.error }\left(\sum_{i=1}^{p} \hat{\varphi}_{i}\right)}
$$

Jika nilai statistik uji $\tau$ lebih kecil dari nilai kritis tabel DF atau tabel MacKinnon, maka hipotesis nol ditolak yang berarti data runtun waktu bersifat stasioner, sedangkan jika nilai statistik uji $\tau$ lebih besar dari nilai kritis DF atau MacKinnon, maka hipotesis nol tidak ditolak yang berarti data runtun bersifat nonstasioner.

\subsection{Vector Autoregressive}

VAR merupakan suatu sistem persamaan yang memperlihatkan setiap variabel sebagai fungsi linear dari konstanta dan nilai lag dari variabel itu sendiri serta nilai lag dari variabel lain yang ada dalam sistem persamaan. Dalam kenyataan sehari-hari, hubungan fungsional antara variabel-variabel ekonomi yang tampaknya sederhana, bisa merupakan suatu proses yang rumit. Model VAR dapat mengatasi permasalahan tersebut, karena model VAR tidak ada penentuan variabel endogen dan eksogen, melainkan semua variabelnya diasumsikan endogen. Berikut adalah bentuk $V A R$ standar dengan banyaknya variabel $n$ dan jumlah lag $\mathrm{p}$ :

$$
\begin{aligned}
\boldsymbol{Y}_{t}= & \boldsymbol{A}_{0}+\boldsymbol{A}_{1} \boldsymbol{Y}_{t-1}+\boldsymbol{A}_{2} \boldsymbol{Y}_{t-2}+\cdots \\
& +\boldsymbol{A}_{p-1} \boldsymbol{Y}_{t-p+1}+\boldsymbol{A}_{p} \boldsymbol{Y}_{t-p}+\boldsymbol{e}_{t}
\end{aligned}
$$

dengan $\boldsymbol{Y}_{t}=\left(\boldsymbol{Y}_{1 t} \boldsymbol{Y}_{2 t} \ldots \boldsymbol{Y}_{(n-1) t} \boldsymbol{Y}_{n t}\right)^{\prime}, \quad \boldsymbol{A}_{0}$ adalah matriks konstanta berukuran $(n \times 1), \boldsymbol{A}_{i}$ adalah matriks koefisien berukuran $(n \times n)$, $i=1,2, \ldots, p$, dan $\boldsymbol{e}_{t}$ adalah vektor galat yang berukuran $(n \times 1)$.

\subsection{Kointegrasi}

Konsep kointegrasi pertama kali dikemukakan oleh Engle \& Granger [4]. Kointegrasi berhubungan erat dengan masalah menentukan suatu hubungan jangka panjang atau keseimbangan jangka panjang. Apabila data runtun waktu terkointegrasi, maka terdapat suatu hubungan jangka panjang di antara data runtun waktu tersebut (Engle \& Granger, [4]).

Ide dasar kointegrasi adalah mencari kombinasi linear di antara dua peubah yang terintegrasi pada orde $d$ yang menghasilkan sebuah peubah dengan orde integrasi yang lebih rendah. Bila variabel runtun waktu tersebut terkointegrasi maka terdapat hubungan yang stabil dalam jangka panjang, bila dua seri tidak stasioner yang terdiri atas $X_{t}$ dan $Y_{t}$ terkointegrasi, maka terdapat representasi khusus sebagai berikut:

$$
\begin{aligned}
& Y_{t}=\beta_{0}+\beta_{1} X_{t}+\mathrm{e}_{t} \\
& \mathrm{e}_{t}=Y_{t}-\beta_{0}-\beta_{1} X_{t}
\end{aligned}
$$

sedemikian rupa hingga $e_{t}$ (error term) stasioner. Kointegrasi dapat dibagi menjadi dua, yaitu kointegrasi bivariat dan multivariat. Pada kasus kointegrasi bivariat, pengujian kointegrasi hanya dilakukan pada dua variabel saja, sedangkan pada kasus multivariat, pengujian kointegrasi dilakukan pada dua variabel atau lebih. Untuk mengetahui apakah data runtun waktu terkointegrasi, maka metode yang dapat digunakan untuk menguji kointegrasi yaitu uji kointegrasi Johansen. Uji kointegrasi menurut Johansen umumnya hanya untuk variabel yang terintegrasi pada orde satu dan orde nol, yaitu $I(1)$ dan $I(0)$. Untuk suatu model $\operatorname{VAR}(p)$, secara umum dapat dinyatakan sebagai:

$$
\Delta \boldsymbol{x}_{t}=\boldsymbol{\Pi} \boldsymbol{x}_{t-1}+\sum_{i=1}^{p-1} \boldsymbol{\Pi}_{i} \Delta \boldsymbol{x}_{t-1}+e_{t} .
$$

Persamaan (7) mengandung informasi baik penyesuaian jangka panjang dan jangka pendek terhadap perubahan $\boldsymbol{x}_{t}$. Rank matriks $\boldsymbol{\Pi}$ ditandai dengan $r, \quad$ menentukan berapa banyak kombinasi linear $\boldsymbol{x}_{t}$ yang bersifat stasioner. Jika $0<r<n$, maka terdapat $r$ vektor kointegrasi atau $r$ kombinasi linear yang stasioner dari $\boldsymbol{x}_{t}$. Dalam kasus ini, $\Pi$ dapat difaktorisasi, sebagai $\Pi=\boldsymbol{\alpha} \boldsymbol{\beta}^{\prime}$, dengan $\boldsymbol{\alpha}$ dan $\boldsymbol{\beta}$ adalah matriks $n \times r$, dengan $\boldsymbol{\alpha}$ mempresentasikan kecepatan penyesuaian terhadap ketidakseimbangan, dan $\boldsymbol{\beta}$ adalah matriks dari koefisien jangka panjang dan mengandung vektor kointegrasi.

Untuk mengetahui jumlah vektor kointegrasi, ada tiga kasus yang perlu dipertimbangkan, yaitu:

a. Jika rank matriks $\Pi=0$, maka tidak ada informasi jangka panjang dan VAR stasioner pada orde nol cocok representasi. 
b. Jika rank matriks $\Pi=\mathrm{n}$, maka $\Pi$ merupakan matriks full rank, sehingga $\boldsymbol{x}_{t}$ stasioner dalam level dan VAR dalam first difference cocok representasi.

c. Jika rank matriks $\Pi$ adalah $0<r<n$, maka $\boldsymbol{\beta}^{\prime} \boldsymbol{x}_{\boldsymbol{t}}$ stasioner walaupun $\boldsymbol{x}_{\boldsymbol{t}}$ tidak stasioner dan bentuk error correction adalah cukup representasi.

Langkah-langkah pengujian kointegrasi Johansen adalah sebagai berikut:

1. Lakukan uji orde integrasi pada $n$ variabel runtun waktu yang ada dengan menggunakan uji ADF.

2. Plot data untuk melihat ada tidaknya tren linear dan intercept dari masing-masing variabel runtun waktu.

3. Pemilihan panjang lag dalam persamaan $V A R$ menggunakan Akaike Information Criterion (AIC) yang dirumuskan sebagai berikut:

$$
\ln (A I C)=\ln \frac{\sum \hat{v}_{i}^{2}}{n}+\frac{2 k}{n}
$$

dengan $\sum \hat{v}_{i}^{2}$ adalah jumlah dari residual kuadrat, $k$ menyatakan jumlah variabel bebas, $n$ menyatakan jumlah observasi.

4. Menguji jumlah hubungan kointegrasi dengan Trace test, yaitu uji untuk mengukur jumlah vektor kointegrasi dalam data runtun waktu dengan menggunakan pengujian rank matriks kointegrasi, dinyatakan:

$$
\lambda_{\text {trace }}(r)=-T \sum_{i=r+1}^{n} \ln \left(1-\hat{\lambda}_{i}\right)
$$

dengan $T$ menyatakan jumlah observasi, $\hat{\lambda}_{i}$ menyatakan estimasi eigenvalue yang dihasilkan dari estimasi matriks П, dan $r$ menyatakan rank yang mengindikasikan jumlah vektor kointegrasi. Dengan mengetahui jumlah $r$, maka akan diketahui jumlah hubungan kointegrasi di antara data runtun waktu.

Hipotesis pengujian:

$H_{0}$ : banyaknya vektor kointegrasi $(r)=0$

$H_{1}$ : banyaknya vektor kointegrasi $(r)>0$

Apabila nilai trace statistic lebih besar dari nilai kritis pada tingkat kepercayaan $\alpha$ adalah 5 $\%$ atau nilai probabilitas lebih kecil dari $\alpha$ adalah $5 \%$ maka hipotesis nol ditolak yang artinya terjadi kointegrasi.

\section{METODE PENELITIAN}

Jenis data yang digunakan dalam penelitian ini adalah data sekunder yang merupakan data yang diperoleh secara tidak langsung, yaitu data Produk Domestik Regional Bruto (PDRB) Provinsi Bali berdasarkan harga konstan Tahun 2000, jumlah kunjungan wisatawan mancanegara (wisman), tingkat inflasi, dan nilai tukar rupiah terhadap dollar Amerika pada bulan Januari 2004 sampai Juni 2014. Untuk data PDRB, jumlah kunjungan wisman, dan tingkat inflasi diperoleh dari Badan Pusat Statistik Provinsi Bali. Sedangkan untuk data nilai tukar rupiah diperoleh dari Bank Indonesia Provinsi Bali.

Langkah-langkah yang dilakukan dalam metode penelitian ini adalah: (a) Menguji kestasioneran data dengan uji akar unit ADF, (b) Menentukan panjang lag optimal, (c) Melakukan uji kointegrasi Johansen (Johansen's Cointegration Test).

\section{HASIL DAN PEMBAHASAN}

\section{A. Uji Kestasioneran Variabel}

Sebelum dilakukan uji kointegrasi maka kestasioneran pada masing-masing variabel perlu diperiksa menggunakan uji Augmented Dickey Fuller (ADF).

Dengan menggunakan uji ADF, maka setiap variabel yang diteliti diasumsikan mengikuti model sebagai berikut:

$$
\begin{aligned}
\triangle P D R B_{t}= & \rho_{1} P D R B_{t-1}+\sum_{i=1}^{m} \phi_{1 i} P D R B_{t-1} \\
& +v_{1 t} \\
\Delta \text { wisman }_{t}= & \rho_{2} \text { wisman }_{t-1} \\
& +\sum_{i=1}^{m} \phi_{2 i} \text { wisman }_{t-1}+v_{2 t}, \\
\text { inflasi }_{t}= & \rho_{3} \text { inflasi }_{t-1} \\
& +\sum_{i=1}^{m} \phi_{3 i} \text { inflasi }_{t-1}+v_{3 t},
\end{aligned}
$$




$$
\begin{aligned}
\Delta k u r s_{t}= & \rho_{4} k_{u r s_{t-1}}+\sum_{i=1}^{m} \phi_{4 i} \text { kurs }_{t-1} \\
& +v_{4 t} .
\end{aligned}
$$

Untuk menggunakan uji ADF pada variabel dalam levelnya, maka untuk masing-masing variabel disusun hipotesis sebagai berikut:

a. Produk Domestik Regional Bruto (PDRB)

$$
\begin{aligned}
H_{0}: \rho_{1}=0 & \text { (PDRB memiliki unit } \\
& \text { root } / \text { tidak stasioner }), \\
H_{1}: \rho_{1}<0 & \text { (PDRB tidak memiliki unit } \\
& \text { root } / \text { stasioner }) .
\end{aligned}
$$

b. Jumlah kunjungan wisman

$$
\begin{aligned}
H_{0}: \rho_{2}=0 & \text { (wisman memiliki unit } \\
& \text { root } / \text { tidak stasioner) } \\
H_{1}: \rho_{2}<0 & \text { (wisman tidak memiliki unit } \\
& \text { root/stasioner) }
\end{aligned}
$$

c. Inflasi

$$
\begin{array}{ll}
H_{0}: \rho_{3}=0 & \text { (inflasi memiliki unit } \\
& \text { root } / \text { tidak stasioner), } \\
H_{1}: \rho_{3}<0 & \text { (inflasi tidak memiliki unit } \\
& \text { root/stasioner). }
\end{array}
$$

d. Nilai tukar

$$
\begin{array}{ll}
H_{0}: \rho_{4}=0 & \text { (kurs memiliki unit root/tidak } \\
& \text { stasioner), } \\
H_{1}: \rho_{4}<0 & \text { (kurs tidak memiliki unit } \\
& \text { root/stasioner). }
\end{array}
$$

untuk masing-masing hipotesis dari variabel yang diteliti kriteria penerimaan $H_{0}$ adalah apabila nilai statistik uji $\tau$ (tau) lebih besar dari nilai kritis pada tabel Dickey-Fuller (DF) atau tabel MacKinnon untuk tingkat kepercayaan $5 \%$ dan nilai probabilitas yang lebih besar dari 0,05 .

Secara ringkas, hasil uji kestasioneran untuk masing-masing variabel pada level menggunakan uji ADF dapat dicantumkan pada Tabel 1.

Tabel 1.Uji Kestasioneran pada Level

\begin{tabular}{|l|l|c|l|}
\hline Variabel & $\begin{array}{l}\text { Nilai } \\
\text { ADF }\end{array}$ & $\begin{array}{l}\text { Nilai Mac- } \\
\text { Kinnon }\end{array}$ & Prob. \\
\hline PDRB & 1.37613 & -2.8872 & 0.9989 \\
\hline Wisman & -1.1314 & -2.8847 & 0.7019 \\
\hline Inflasi & -9.0417 & -2.8848 & 0.0000 \\
\hline Kurs & -1.8606 & -2.8852 & 0.3499 \\
\hline
\end{tabular}

Tabel 1 memperlihatkan variabel inflasi stasioner pada orde nol atau $I(0)$, dengan nilai statistik uji $\tau$ lebih kecil dari nilai kritis pada tabel DF atau tabel MacKinnon untuk tingkat keyakinan 5\% dan nilai probabilitas yang lebih kecil dari 0,05. Agar variabel-variabel yang lain juga stasioner, maka perlu diasumsikan variabel-variabel tersebut menuju stasioner pada orde satu atau I(1).

\section{B. Penentuan Panjang Lag Optimal}

Setelah menguji kestasioneran data, maka langkah selanjutnya adalah menentukan panjang lag yang optimal. Mengingat bahwa estimasi VAR sangat peka terhadap panjang lag yang digunakan, maka berdasarkan kriteria yang digunakan yaitu Akaike Information Criterion (AIC) dengan menggunakan software EViews 6 diperoleh panjang lag yang optimal adalah empat (ditandai dengan tanda *). Seperti pada Tabel 2 berikut:

Tabel 2. Panjang Lag Optimal

\begin{tabular}{|c|c|}
\hline Lag & AIC \\
\hline 0 & 68.08185 \\
\hline 1 & 60.52098 \\
\hline 2 & 60.28535 \\
\hline 3 & 60.36763 \\
\hline 4 & 59.98173 \\
\hline 5 & $59.95640^{*}$ \\
\hline 6 & 60.03452 \\
\hline 7 & 60.00008 \\
\hline 8 & 60.02230 \\
\hline
\end{tabular}

\section{Uji Kointegrasi Johansen}

Berdasarkan panjang lag tersebut, selanjutnya dilakukan uji kointegrasi. Dalam penelitian ini, uji kointegrasi dilakukan dengan menggunakan metode Johansen. Variabelvariabel yang akan diuji harus merupakan variabel yang stasioner pada derajat yang sama atau pada orde $d$, yaitu jumlah kunjungan wisman, nilai tukar dan PDRB Provinsi Bali. Berikut ini dicantumkan tabel hasil uji kointegrasi dengan metode Johansen pada Tabel 3 dan Tabel 4 dengan hipotesis sebagai berikut: 
$H_{0}$ : banyaknya vektor kointegrasi $(r)=0$, $H_{1}$ : banyaknya vektor kointegrasi $(r)>0$.

Apabila nilai trace statistic dan maximum eigenvalue lebih besar dari nilai kritis pada tingkat kepercayaan $\alpha$ adalah $5 \%$ atau nilai probabilitas lebih kecil dari $\alpha$ adalah $5 \%$ maka hipotesis nol ditolak yang artinya terjadi kointegrasi.

Tabel 3. Johansen's Contegration Test (trace statistics)

\begin{tabular}{|c|c|c|c|c|}
\hline$H_{0}$ & $\begin{array}{c}\text { Eigenv } \\
\text { alue }\end{array}$ & $\begin{array}{c}\text { Trace } \\
\text { Statistic }\end{array}$ & $\begin{array}{c}5 \% \\
\text { Critical } \\
\text { Value }\end{array}$ & Prob. \\
\hline$r=0$ & 0.1109 & 19.3115 & 29.7970 & 0.4707 \\
\hline$r \leq 1$ & 0.0410 & 5.21089 & 15.4947 & 0.7860 \\
\hline$r \leq 2$ & 0.0016 & 0.18723 & 3.84147 & 0.6652 \\
\hline
\end{tabular}

*denotes rejection of the hypothesis at the 0.05 level

Tabel 4. Johansen's Contegration Test (maximum eigenvalue statistics)

\begin{tabular}{|c|c|c|c|c|}
\hline$H_{0}$ & $\begin{array}{c}\text { Eigenv } \\
\text { alue }\end{array}$ & $\begin{array}{c}\text { Max- } \\
\text { Eigen } \\
\text { Statistic }\end{array}$ & $\begin{array}{c}5 \% \\
\text { Critical } \\
\text { Value }\end{array}$ & Prob. \\
\hline$r=0$ & 0.1109 & 14.1007 & 21.1316 & 0.3568 \\
\hline$r \leq 1$ & 0.0410 & 5.02367 & 14.2646 & 0.7388 \\
\hline$r \leq 2$ & 0.0016 & 0.18723 & 3.84147 & 0.6652 \\
\hline
\end{tabular}

$*$ denotes rejection of the hypothesis at the 0.05 level Sumber: Analisis Data (2015)

Tabel 3 dan Tabel 4 di atas dapat dilihat bahwa nilai trace statistic dan maximum eigenvalue pada $r=0$ lebih kecil dari critical value dengan tingkat signifikansi 5\%. Hal ini berarti hipotesis nol yang menyatakan bahwa tidak ada kointegrasi tidak dapat ditolak dan hipotesis alternatif yang menyatakan bahwa ada kointegrasi ditolak.

Berdasarkan analisis di atas dapat dilihat bahwa di antara ketiga variabel dalam penelitian ini tidak terdapat kointegrasi pada tingkat signifikansi 5\%. Dengan demikian, dari hasil uji kointegrasi mengindikasikan bahwa di antara jumlah kunjungan wisman, inflasi, nilai tukar dan PDRB tidak memiliki keseimbangan jangka panjang (long-run equilibrium). Karena hasil pengujian kointegrasi Johansen memperlihatkan tidak terdapat keseimbangan jangka panjang, maka dilakukan estimasi hubungan jangka pendek dari variabel-variabel tersebut menggunakan uji Error Correction
Model (ECM). Dengan menggunakan software EViews 6, maka bentuk persamaan ECM adalah:

$$
\begin{array}{rl}
\Delta P D R B_{t}=1 & 0879,34 \\
& +0,405693 \Delta \text { WISMAN }_{t} \\
& -3,629087 \Delta K U R S_{t} \\
& -0,077560 \Delta E C T_{t-1}
\end{array}
$$

Berdasarkan hasil uji ECM diperoleh nilai probabilitas ECT yaitu 0,0002. Nilai ini kurang dari nilai $\alpha$ yang digunakan yaitu 5\%, sehingga dapat disimpulkan variabel ECT signifikan.Ini berarti bahwa persamaan (8) merupakan model yang valid untuk menggambarkan dinamika jangka pendek.

Persamaan (8) memperlihatkan PDRB pada waktu ke- $t$ akan dipengaruhi sebuah konstanta sebesar 10879,34. Secara umum kunjungan wisatawan memberikan pengaruh yang positif dalam jangka pendek. Pengaruh yang diberikan terhadap PDRB Provinsi Bali adalah sebesar koefisien pada periodenya. Hal ini mengindikasikan bahwa hubungan antara jumlah kunjungan wisman dan PDRB searah. Meningkatnya jumlah kunjungan wisman mengakibatkan jumlah pendapatan PDRB Provinsi Bali bertambah. Hasil yang berbeda ditunjukkan variabel nilai tukar rupiah terhadap dollar Amerika Serikat. Secara umum nilai tukar rupiah memberikan pengaruh yang negatif dalam jangka pendek. Pengaruh yang diberikan terhadap PDRB Provinsi Bali adalah sebesar koefisien pada periodenya. Hal ini mengindikasikan bahwa hubungan antara nilai tukar rupiah dan PDRB berlawanan arah. Menguatnya nilai tukar rupiah terhadap dollar Amerika Serikat mengakibatkan jumlah pendapatan PDRB Provinsi Bali berkurang.

\section{SIMPULAN DAN REKOMENDASI}

Berdasarkan uraian pada hasil dan pembahasan, maka diperoleh beberapa simpulan, yaitu:

1. Tidak terdapat keseimbangan jangka panjang (long-run equilibrium) antara variabel jumlah kunjungan wisatawan mancanegara (wisman), inflasi, nilai tukar rupiah terhadap dollar Amerika Serikat dan 
produk domestik regional bruto (PDRB) Provinsi Bali;

2. Memerhatikan bahwa tidak terjadi keseimbangan jangka panjang (long-run equilibrium), maka tidak bisa disimpulkan untuk model persamaan struktural antara variabel jumlah kunjungan wisatawan mancanegara (wisman), inflasi, nilai tukar rupiah terhadap dollar Amerika Serikat dan produk domestik regional bruto (PDRB) Provinsi Bali.

Untuk penelitian selanjutnya dapat menambahkan beberapa variabel-variabel lain yang memengaruhi PDRB Provinsi Bali. Selain itu, peneliti juga dapat menggunakan multicointegration, atau menambahkan uji kausalitas Granger, Impulse Respons Function, dan Variance Decomposition ataupun metodemetode lain yang mendukung uji kointegrasi Johansen.

\section{DAFTAR PUSTAKA}

[1] Box, G.E.P. \& Jenkins, G.M., 1970. Time Series Analysis: Forecasting and Control. San Fransisco: Holden Day.

[2] Dickey, D.A. \& Fuller, W.A.,1981. Likelihood Ratio Statistics for Autoregressive Time Series With a Unit Root. Econometrica, vol.49, no.4, pp.1057-1072.

[3] Enders, W., 2010. Applied Econometric Time Series. $2^{\text {nd }}$ ed. New York: John Willey \& Sons, Inc.

[4] Engle, R.F. \& Granger, C.W.J., 1987. CoIntegration and Error Correction: Representation, Estimation, and Testing. Econometrica, vol.55, no.2, pp.251-276.

[5] Gujarati, D.N., 2004. Basic Econometrics. $4^{\text {th }}$ ed. New York: The McGraw-Hill. 